\title{
The northern hemisphere circumglobal teleconnection in a seasonal forecast model and its relationship to European summer forecast skill
}

\author{
Jonathan D. Beverley ${ }^{1}$ (D) Steven J. Woolnough ${ }^{2}$ (D) Laura H. Baker ${ }^{2}$ (i) - Stephanie J. Johnson ${ }^{3}$. \\ Antje Weisheimer ${ }^{3,4}$ (1)
}

Received: 5 March 2018 / Accepted: 7 July 2018 / Published online: 28 July 2018

(c) The Author(s) 2018

\begin{abstract}
Forecasting seasonal variations in European summer weather represents a considerable challenge. Here, we assess the performance of a seasonal forecasting model at representing a major mode of northern hemisphere summer climate variability, the circumglobal teleconnection (CGT), and the implications of errors in its representation on seasonal forecasts for the European summer (June, July, August). Using seasonal hindcasts initialised at the start of May, we find that the model skill for forecasting the interannual variability of $500 \mathrm{hPa}$ geopotential height is poor, particularly over Europe and several other "centres of action" of the CGT. The model also has a weaker CGT pattern than is observed, particularly in August, when the observed CGT wavetrain is strongest. We investigate several potential causes of this poor skill. First, model variance in geopotential height in west-central Asia (an important region for the maintenance of the CGT) is lower than observed in July and August, associated with a poor representation of the link between this region and Indian monsoon precipitation. Second, analysis of the Rossby wave source shows that the source associated with monsoon heating is both too strong and displaced to the northeast in the model. This is related to errors in monsoon precipitation over the Bay of Bengal and Arabian Sea, where the model has more precipitation than is observed. Third, the model jet is systematically shifted northwards by several degrees latitude over large parts of the northern hemisphere, which may affect the propagation characteristics of Rossby waves in the model.
\end{abstract}

Keywords Seasonal forecasting $\cdot$ Teleconnection $\cdot$ Indian monsoon

\section{Introduction}

Variations in precipitation and temperature in the European summer can have severe and wide-reaching effects, both on society and on governments and businesses in the affected regions. Events such as the central European heatwave of

Jonathan D. Beverley

j.beverley@pgr.reading.ac.uk

1 Department of Meteorology, University of Reading, Earley Gate, Reading RG6 6BB, UK

2 Department of Meteorology, National Centre for Atmospheric Science, University of Reading, Earley Gate, Reading RG6 6BB, UK

3 ECMWF, Shinfield Park, Reading RG2 9AX, UK

4 Department of Physics, National Centre for Atmospheric Science (NCAS), University of Oxford, Oxford OX1 3PU, UK
2003 and flooding in the UK in 2007 highlighted the vulnerability of society to extremes of climate anomalies.

Recent research has led to improvements in European winter seasonal forecasts (e.g. Scaife et al. 2011; Stockdale et al. 2015; Dunstone et al. 2016), however there has been less of a focus on the summer season and forecast skill remains relatively low. The European climate is affected by a large range of influences, including from tropical regions, and better understanding of the mechanisms behind these tropical-extratropical teleconnections can inform our evaluation of seasonal forecast systems and priorities for model development.

It is difficult to predict European summer weather and climate on forecast lead times of longer than a few days. This is partially due to the range of large-scale circulation patterns that affect the European climate. The Atlantic jet and the associated storm track are the dominant circulation systems affecting the European summer climate. The Summer North Atlantic Oscillation (SNAO, Folland et al. 2009) 
is the leading mode of variability in the Atlantic/European sector and it is dominated by north-south shifts of the jet and storm track. This is also linked to persistent areas of high surface pressure, known as blocking events. These are well known for their impact during the winter, but they also cause severe impacts during the summer, including droughts and heatwaves. Blocking areas of high pressure can persist for several weeks and thus can affect the circulation in Europe for prolonged periods (Rex 1950). A further influence of summertime variability is planetary Rossby wave activity. Summertime Rossby wave activity plays an important role in northern hemisphere teleconnection mechanisms. Stationary, or low frequency, Rossby waves are of particular importance when the anomalies remain stationary with respect to the ground. The persistence of local weather anomalies associated with Rossby waves such as these over long periods is a common factor in high-impact weather events (Blackburn et al. 2008). The geopotential anomalies associated with the circumglobal teleconnection (CGT) will modify the location of the jet stream in the North Atlantic, affecting the propagation of weather systems, the location of blocking events and the propagation of stationary Rossby waves.

As shown by Sardeshmukh and Hoskins (1988), the convective heat source over the Bay of Bengal and the Indian Summer Monsoon (ISM) region and its associated upper tropospheric divergence can serve as a Rossby wave source. This wave activity is a potential source of seasonal predictability in the extratropics. Of the global monsoon systems, the ISM has been identified as having a possible impact on European summer climate. Rodwell and Hoskins (1996) used an idealised model to show, through imposing an off-equatorial heating in the ISM region, that upper tropospheric divergence associated with diabatic heating in the ISM region can induce a Rossby wave pattern to the west. They also showed that the interaction of the Rossby wave with the midlatitude westerlies on its northern flank can lead to enhanced descent over the Mediterranean and northern Africa, thus reducing the precipitation in these areas. Raicich et al. (2003) found significant correlations between an Indian monsoon index and sea level pressure over the eastern Mediterranean during the summer, and Tyrlis et al. (2014) also found a link between the ISM and tropopause fold activity over the eastern Mediterranean and the Middle East, with an upward trend in fold activity as a result of the monsoon onset.

The CGT was first identified by Ding and Wang (2005) as having a major role in modulating observed weather patterns in the northern hemisphere summer. Using a 200 $\mathrm{hPa}$ geopotential height index centred in west-central Asia $\left(35^{\circ}-40^{\circ} \mathrm{N}, 60^{\circ}-70^{\circ} \mathrm{E}\right.$, hereafter the $\mathrm{D} \& \mathrm{~W}$ Index $)$, an area which has large standard deviation in $200 \mathrm{hPa}$ geopotential height, they constructed a one-point correlation map of JJAS geopotential height with reference to this index (reproduced in Fig. 2 using ERA-Interim data). From this, they identified a wavenumber-5 structure where the pressure variations over the northeast Atlantic, east Asia, North Pacific and North America are all nearly in phase with the variations over west-central Asia.

The CGT has been shown to be a source of climate variability and predictability in the northern hemisphere summer on intraseasonal (Ding and Wang 2007; Moon et al. 2013), seasonal (Ding and Wang 2005; Lee et al. 2011; Ha et al. 2012) and interannual timescales (Ding et al. 2011). It has significant impacts on precipitation and temperature anomalies across the northern hemisphere. Ding and Wang (2005) showed that the strongest effects over Europe occur in August, when there are significant negative precipitation anomalies over the UK and parts of Scandinavia. They also found significant positive correlations between west-central Asia geopotential height and precipitation across parts of the Mediterranean during August. Saeed et al. (2014) also found that the positive phase of the CGT, which is associated with upper level anomalous low pressure over western Europe, causes significantly enhanced precipitation over western Europe and reduced precipitation over eastern Europe.

Ding and Wang (2007) hypothesised that the ISM is also important in the maintenance of the CGT. Convection over the north ISM (NISM) region is initially triggered by the anomalous central Asian high, which itself is generated through the propagation of Rossby waves from the jet exit region over northwest Europe to west-central Asia. This convection and associated diabatic heating in turn excites a Rossby wave response, which reinforces the west-central Asian high, and this then enhances downstream circulation anomalies through the propagation of these waves along the waveguide (the westerly jet) (Liu and Wang 2013).

Ding and Wang (2005) also used composite analysis to show that the D\&W Index is related to precipitation over the Indian subcontinent, particularly during June-July. During June, the relationship is associated with precipitation in the monsoon trough region in the northeast of India, when the area of highest positive anomalies approximately follows the path taken by monsoon depressions which bring a large amount of rainfall to this region of India (Godbole 1977). In July and August the area of highest positive anomalies has moved to the northern and western parts of India, but the overall relationship between the D\&W Index and rainfall in the ISM region remains significant.

The ISM exhibits large variability on interannual and intraseasonal timescales. Interannual variability is strongly correlated with El Niño Southern Oscillation (ENSO, e.g. Shukla and Paolino 1983; Ropelewski and Halpert 1987) and the Indian Ocean Dipole (Ashok et al. 2001). Its relationship with these coupled modes of variability provides a source of predictability for the ISM on seasonal timescales. 
Operational forecast models have been shown to have skill for the ISM (Kim et al. 2012; Rajeevan et al. 2012; Sperber et al. 2013; Johnson et al. 2016) so if the CGT is driven by ISM variability then this may provide a source of predictability for European summer weather.

This study aims to evaluate the performance of the ECMWF seasonal forecast model (Cycle 41R1) at representing the CGT, and the link between errors in its representation and poor forecast skill over Europe. In Sect. 2 we describe the model, data and analysis techniques used. In Sect. 3 we analyse the overall skill of the model, and its performance at simulating the CGT. In Sect. 4 we determine several possible reasons for the errors seen in the model representation of the CGT. We conclude in Sect. 5.

\section{Data and method}

\subsection{Model}

The model used for the hindcasts is version CY41R1 of the European Centre for Medium-Range Weather Forecasts (ECMWF)'s Integrated Forecasting System model (IFS), coupled to the Nucleus for European Modelling of the Ocean model (NEMO). This atmospheric model version is a more recent one than in the former operational model, System 4 (Molteni et al. 2011), but older than the recently introduced System 5. The horizontal spectral resolution of the atmospheric model (T255) is the same as System 4 and corresponds to a grid length of approximately $80 \mathrm{~km}$ with 91 vertical levels, with the model top at $0.01 \mathrm{hPa}$, while the ocean model has a resolution of approximately 1 degree with 42 vertical levels (Weisheimer et al. 2017). The hindcasts were performed using the ECMWF ERA-Interim and ORAS4 reanalyses for initialisation of the atmosphere and ocean, respectively. Seasonal hindcasts over four months, with 25 ensemble members, were initialised on 1st May for the period 1981-2014, therefore covering the boreal summer season of June-August (JJA) and much of the ISM season, and the analysis presented here uses monthly mean values for May-August from these hindcast runs.

\subsection{Verifying data}

Observational atmospheric monthly mean fields come from ERA-Interim reanalysis (Dee et al. 2011) at $80 \mathrm{~km}$ resolution for the period 1981-2014. Observations of precipitation come from the Global Precipitation Climatology Project (GPCP) dataset (Adler et al. 2003). In order to focus on yearto-year variations, we only use the interannual component of the data. We performed Fourier harmonic analysis on the monthly mean data to remove the long term trend and decadal variations with a period of longer than 8.5 years. A Student's $t$ test was used to assess the statistical significance of calculated correlation values (Wilks 2011).

\subsection{Multiple sampling}

The ECMWF forecast system provides us with multiple realisations in the form of 25 ensemble members. When analysing model output, a common technique is to use the ensemble mean. However, using the ensemble mean reduces the noise and the contribution of the forced variability is increased relative to the total variability. Therefore, to ensure that we do not mistake noise in the observations for forced variability, we need to compare individual ensemble members from the hindcast dataset to the observations. To do this, we follow the method of Johnson et al. (2016) and construct many timeseries of monthly averaged variables by randomly selecting an ensemble member from each year and repeating this until we have 2000 sets of timeseries, of 34 years each. We are then able to compare the single realisation of the observed system to multiple realisations of the simulated system.

\section{Diagnosing model performance}

\subsection{Forecast skill}

As a first order measure of model forecast skill we examine the ensemble mean skill for $500 \mathrm{hPa}$ geopotential height in the northern hemisphere (Fig. 1). For the first month of the forecast the model has good skill across the northern hemisphere, with positive correlations everywhere. However, in June, July and August the skill is much reduced, with large areas of negative correlation (no skill) developing over many regions, including much of Europe.

Figure 2 shows the observed CGT pattern as defined in Ding and Wang (2005) as the correlation between the D\&W Index and $200 \mathrm{hPa}$ geopotential height elsewhere, using ERA-Interim data (1981-2014 to align with the model forecast period) for May-August. Of the four months, May has the weakest CGT pattern, with little evidence of a wavetrain outside of Asia and so we will not focus on May from hereon. However, there is more evidence of a CGT pattern in June-August. In June, the correlation pattern is dominated by a region of positive correlation to the west of the $\mathrm{D} \& \mathrm{~W}$ region, extending across the Sahara and parts of the Mediterranean. This is related to the monsoon-desert mechanism proposed by Rodwell and Hoskins (1996), where there is a westward retreat of the west-central Asian high following the onset of the monsoon at the beginning of June. There are also areas of significant positive correlation located in east Asia and the North Pacific, although there is little signal 

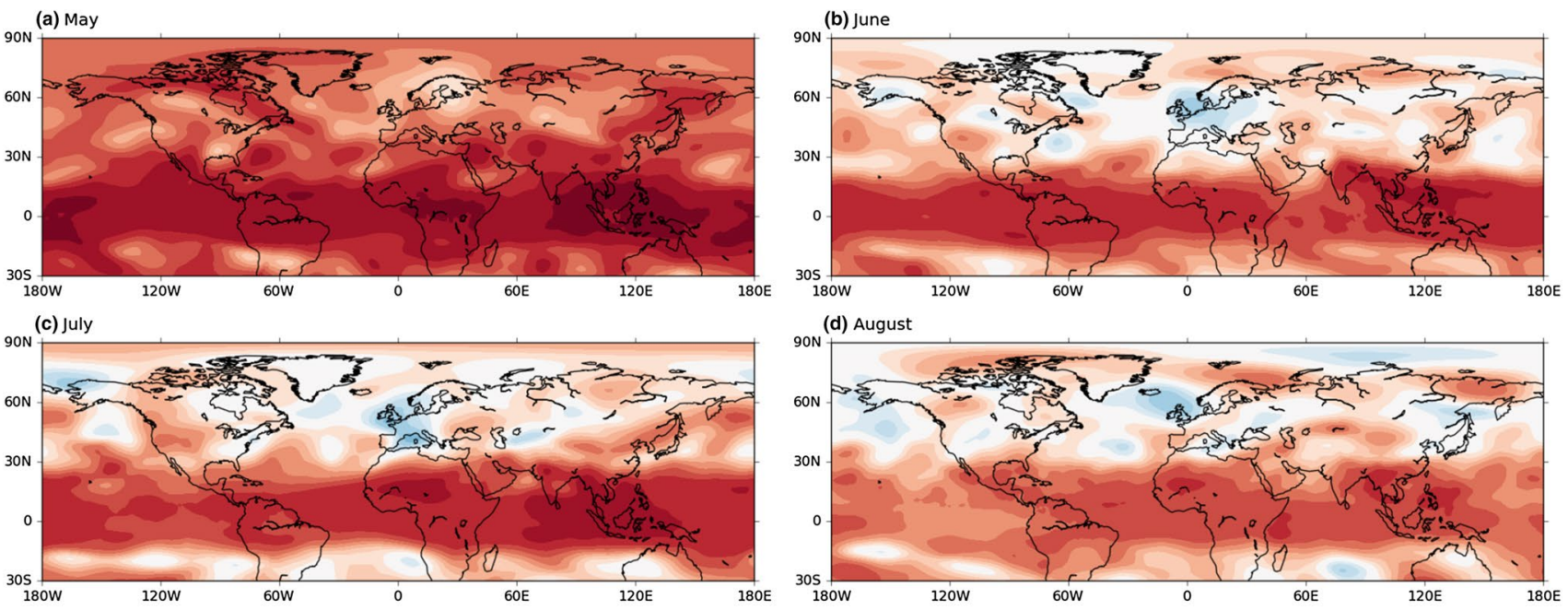

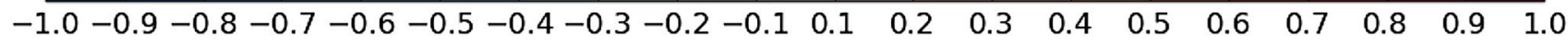

Fig. 1 Model ensemble mean skill for $500 \mathrm{hPa}$ geopotential height as defined as the correlation between ERA-Interim and model ensemble mean for a May, b June, c July and d August
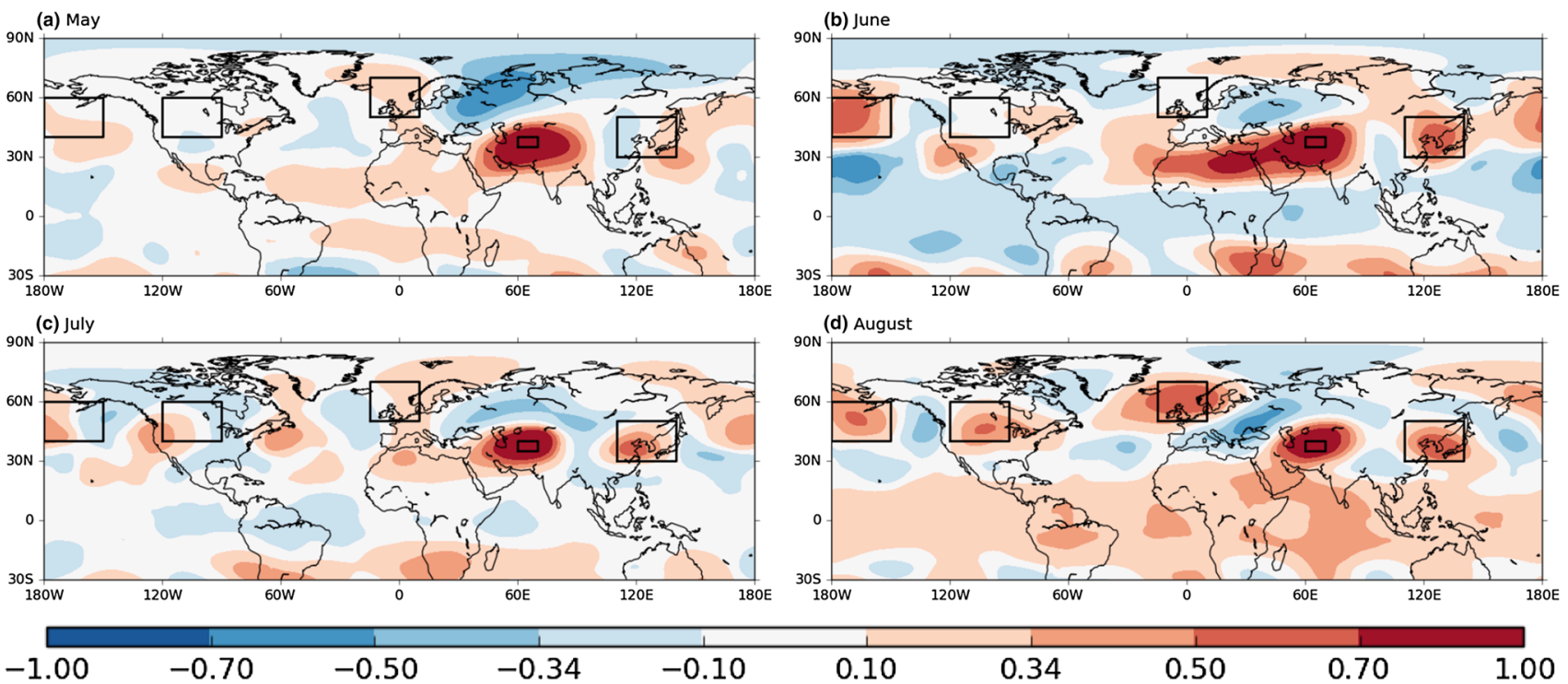

$-1.00 \quad-0.70 \quad-0.50 \quad-0.34 \quad-0.10$

Fig. 2 One-point correlation between $200 \mathrm{hPa}$ geopotential at the base point $\left(\mathrm{D} \& \mathrm{~W}\right.$ region, $\left.35^{\circ}-40^{\circ} \mathrm{N}, 60^{\circ}-70^{\circ} \mathrm{E}\right)$ and $200 \mathrm{hPa}$ geopotential elsewhere in the ERA-Interim (1981-2014) reanalysis data-

set, for a May, b June, c July and $\mathbf{d}$ August. Correlation values of \pm 0.34 are significant at the $5 \%$ level. The boxes indicate the regions defined as the "centres of action" of the CGT

over North America and western Europe. In July a wavetrain is visible at around $45^{\circ} \mathrm{N}$ which has a wavenumber- 6 structure. In August the CGT pattern becomes stronger due to the enhanced Asian jet (Enomoto et al. 2003), and the locations of the correlation centres shifts slightly compared to July associated with a change to a wavenumber-5 structure. As August has the strongest CGT pattern, we define several geopotential height indices based on the correlation pattern in this month. These are overlayed as boxes on Fig. 2, and
Table 1 CGT $200 \mathrm{hPa}$ geopotential height indices

\begin{tabular}{lll}
\hline Index & Abbreviation & Domain \\
\hline Ding and Wang & D\&W & $60^{\circ}-70^{\circ} \mathrm{E}, 35^{\circ}-40^{\circ} \mathrm{N}$ \\
Northwest Europe & NWEUR & $15^{\circ} \mathrm{W}-10^{\circ} \mathrm{E}, 50^{\circ}-70^{\circ} \mathrm{N}$ \\
East Asia & EASIA & $110^{\circ}-140^{\circ} \mathrm{E}, 30^{\circ}-50^{\circ} \mathrm{N}$ \\
North Pacific & NPAC & $180^{\circ}-150^{\circ} \mathrm{W}, 40^{\circ}-60^{\circ} \mathrm{N}$ \\
North America & NAM & $120^{\circ}-90^{\circ} \mathrm{W}, 40^{\circ}-60^{\circ} \mathrm{N}$ \\
\hline
\end{tabular}


are also listed in Table 1, and we refer to them as "centres of action" of the CGT.

In August there are particularly strong correlations between the northwest Europe (NWEUR), Ding and Wang (D\&W), East Asia (EASIA) and North Pacific (NPAC) regions. The weaker correlation between the NPAC and North America (NAM) and NAM and NWEUR regions perhaps suggests that the NAM region is less instrumental in the CGT, and an observed correlation of 0.46 in August (when the CGT is strongest) between the NPAC and NWEUR regions (bypassing the NAM region) supports this. The similarity between the location of the CGT centres of action and the areas of reduced model skill for geopotential height in Fig. 1 is one of the main motivations for this paper.

The observed CGT pattern has a slightly different phase in July, and to a lesser extend in June, compared to August. This means that the boxes used for the indices, which are defined based on the August pattern, are not all aligned with the centres of positive correlation in June and July. This may partly account for some of the differences in observed and model correlations between different regions seen later in the paper.

\subsection{Model representation of the CGT}

We now examine the representation of the CGT in the model. One-point correlations with the D\&W Index are shown in Fig. 3. In order to get an idea of the mean model response, but without using the ensemble mean (which will over-emphasise the forced response), these correlations were calculated for each of the 25 ensemble members, and the average of these 25 correlations maps was taken. In June, the model accurately captures the effect of the Rodwell and Hoskins mechanism, visible in the westward lobe of positive correlations extending from the D\&W region, albeit with slightly less of a westward extension and slightly weaker magnitude than is observed, and the pattern correlation is 0.81 . The centre of action over east Asia is also very accurately simulated, in both location and magnitude, and this seems to be one area in which the model does well in all months. By July the model has developed a weak positive correlation across much of the northern hemisphere and the tropics and this contributes towards a reduced pattern correlation (0.60). Although the pattern correlation increases slightly in August (0.70), the correlations at the centres of action are still much too weak. The negative correlations, particularly in August, are virtually non-existent, probably in part as a result of the developing hemisphere-wide positive correlation.

We now look in more detail at the relationships between the CGT centres of action in the model, and how they differ from observations. To do this, we use the method described in Sect. 2.3 to generate multiple timeseries from the ensemble forecast and use these to perform correlation analysis between the D\&W Index and the other CGT indices, which are listed in Table 1 and shown as boxes on Figs. 2 and 3. We can then use these multiple samples to determine whether the model correlation is consistent with observations. If it is not, then either the model is good and the observed pattern has a very low probability of occurence, or the model is unable to capture the observed teleconnection pattern.

Figure 4 shows the distributions of the correlation values between the D\&W Index and the other centres of action of the CGT for both the model and ERA-Interim for JJA. As
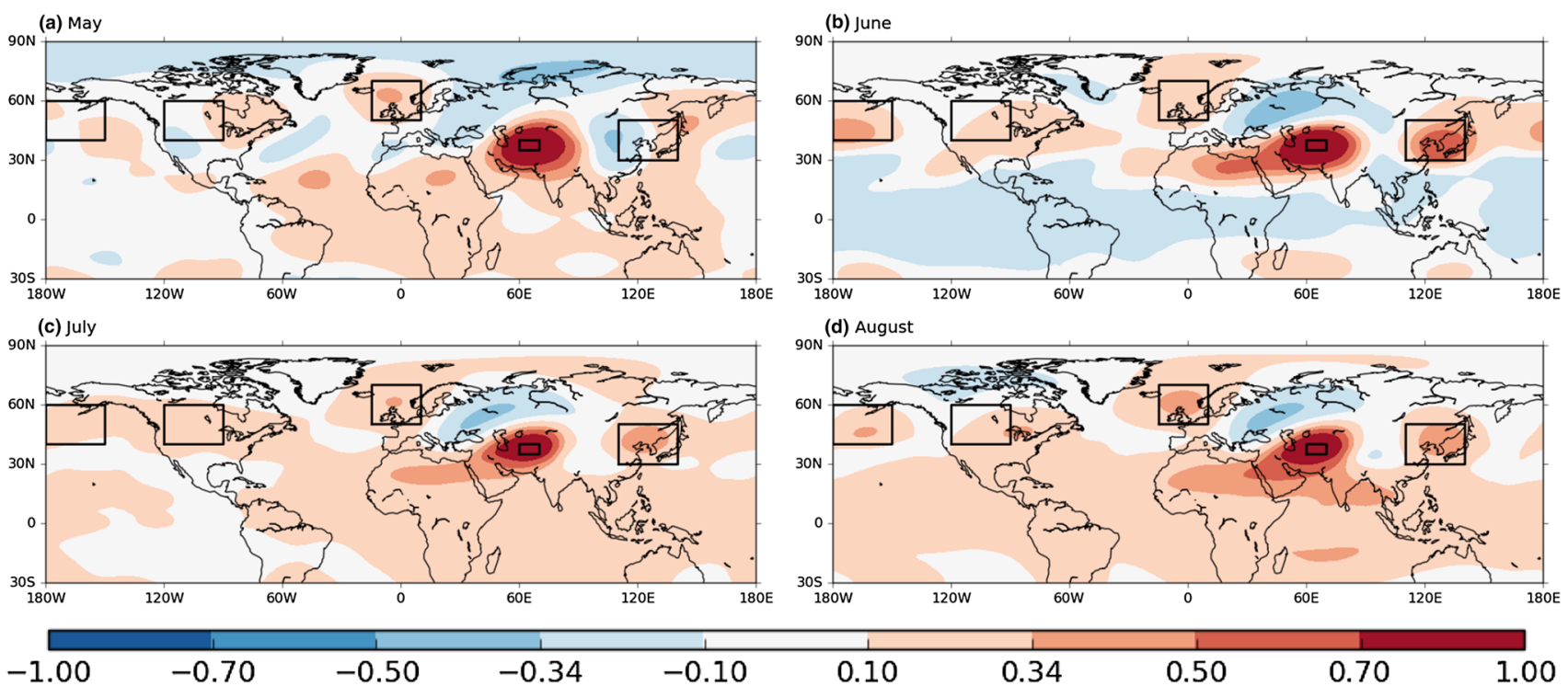

$-1.00$

$-0.70$

$-0.50$

$-0.34$

$-0.10$

0.10

0.34

0.50

0.70

1.00

Fig. 3 Same as Fig. 2, except the average of 25 ensemble member correlations for the model hindcasts, for a May, b June, c July and d August 


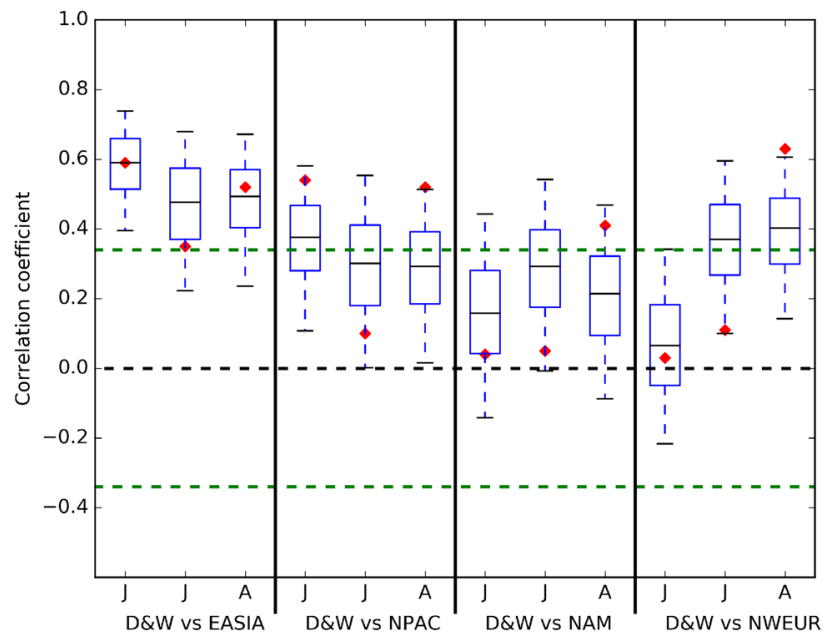

Fig. 4 Distribution of correlation coefficients for the D\&W Index correlated against the other centres of action of the CGT, calculated using the multiple samples. The box plots represent the upper and lower quartiles, and the whiskers extend to the 5th and 95th percentiles. The black horizontal line represents the median value and the red diamond the observed correlation coefficient from ERA-Interim. $5 \%$ significance levels $( \pm 0.34)$ are indicated by the green dashed lines

expected, the correlation with the D\&W Index decreases further downstream from this region. The representation by the model of the relationship between the D\&W Index and the EASIA region is generally very good, with the observed correlation falling between the 20th and 80th percentiles in all three months. Wu et al. (2016) suggested a link between East Asian Summer Monsoon precipitation and the CGT, via the Pacific-Japan (PJ) pattern. Our analysis suggests that while the PJ pattern has a weak but significant positive correlation with the EASIA region in July (0.40), the correlation with the DW region is negative (-0.33), suggesting that the relationship between the PJ pattern and the EASIA region is independent of the CGT. The model is not as good at capturing the relationship between the $\mathrm{D} \& \mathrm{~W}$ Index and the other centres of action. The performance in August is the worst, with the observed correlation between the D\&W Index and the NPAC, NAM and NWEUR regions all falling in the 90th percentile or above, meaning that the model underestimates the link between these regions in August. This corroborates what is shown in Fig. 3, that the modelled CGT correlations are much too weak in August. In general, the model tends to overestimate the strength of the correlations in July, and underestimates them in August. This is potentially related to the difference in the observed CGT wavetrain in July compared to August. In July, the CGT has a wavenumber-6 structure, with the NPAC and NAM centres of action displaced westwards relative to August, when there is a wavenumber-5 structure. This means that in July there are both positive and negative contributions from the correlations in these centres

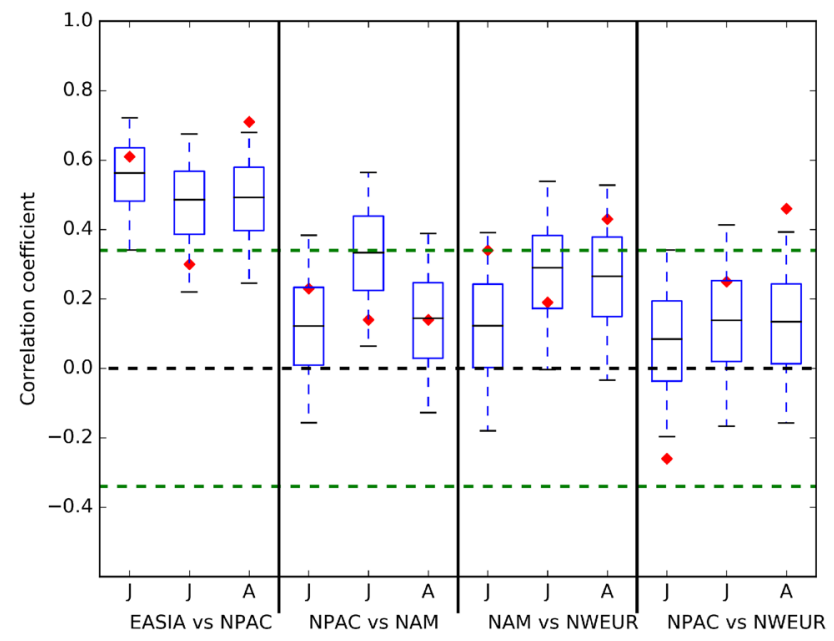

Fig. 5 Same as Fig. 4, but for each centre of action of the CGT against the neighbouring centre of action

of action, and so the observed July correlations are reduced compared to August. As the correlations in the model in July and August are of similar magnitude, this suggests that the model does not capture the difference in the CGT wavenumber between these months and has a wavenumber- 5 structure in both. The observed CGT is strongest in August and is related to significant temperature and precipitation anomalies in Europe in this month, so the inability of the model to capture the strength of the relationship between the D\&W Index and these centres of action may impact on forecast skill for these variables.

Figure 5 shows the distribution of model correlations between each CGT centre of action and its neighbouring centres of action. It was shown in Fig. 4 that the model representation of the relationship between the $\mathrm{D} \& \mathrm{~W}$ region and EASIA region is good. However, the model is less able to capture the relationships between subsequent downstream centres of action. The relationship between the EASIA and NPAC regions is good in June, but in July the model overestimates the magnitude of the correlation between these regions. As previously mentioned, this is in part due to the slightly different spatial structure of the CGT correlations in July, with the NPAC centre of action shifted westwards towards the date line, and an area of negative correlations in its place. In August there is an observed correlation of 0.71 between these regions, but this falls in the 98th percentile of the distribution with an ensemble median correlation of around 0.50 . As the model underestimates the strength of the relationship between these regions in August, this limits the ability of the model to represent the August CGT accurately and will also affect the subsequent downstream representation of the CGT.

The observed correlations between the NPAC and NAM regions are not significant in all months. The model captures 
this with a reasonable degree of success, with the observations lying between the 10th and 90th percentiles in all months, although the model does overestimate the magnitude of the correlation in July. The observed correlations between the NAM and NWEUR regions are significant in June and August ( 0.34 and 0.43 respectively). For both months the observations lie within the spread of the model distribution, although the median of the model correlations is lower than observed in both cases.

There is an observed correlation of 0.46 between the NPAC and NWEUR regions (bypassing the NAM region) in August. The model underestimates the strength of this correlation by a large margin, and this is consistent with correlations between other regions, where the correlations tend to be underestimated by the model in August associated with a weaker than observed CGT.

\section{Understanding errors in the model teleconnection}

There are a number of possible causes of the errors in the model representation of the CGT. There may be errors in the way that it is forced, or errors relating to wave propagation within the model. The propagation of Rossby waves is an important part of the CGT mechanism, thus differences in the Rossby wave propagation characteristics between model and observations, possibly related to errors in the Rossby wave source or jet biases, have the potential to cause large errors in the CGT. We now examine several of these possible causes and determine the role that each has in causing errors in the teleconnection.

\subsection{Errors in the $D \& W$ region}

We first look at the variance of the D\&W Index in the model compared to observations, noting that if the model variability in that region is small, the variance associated with that in other centres of action may be reduced. If the variance is weak, it is an indication that the region is not being forced as it should be. If the variance is strong, this suggests that it is the model teleconnection mechanism that is wrong.

Figure 6 shows the distribution of the variance of the D\&W Index in the model and observations. The variance of the D\&W Index is greatest in June, and the model reflects this, with the observations lying well within the interquartile range of the model distribution. However, in July and August the model underestimates the variance in this region, most notably in July when the observed variance falls well outside of the model distribution. In August the observed variance does lie within the model distribution but falls in the 92 nd percentile. The underestimation of the variance in this region by the model suggests that even if the teleconnection

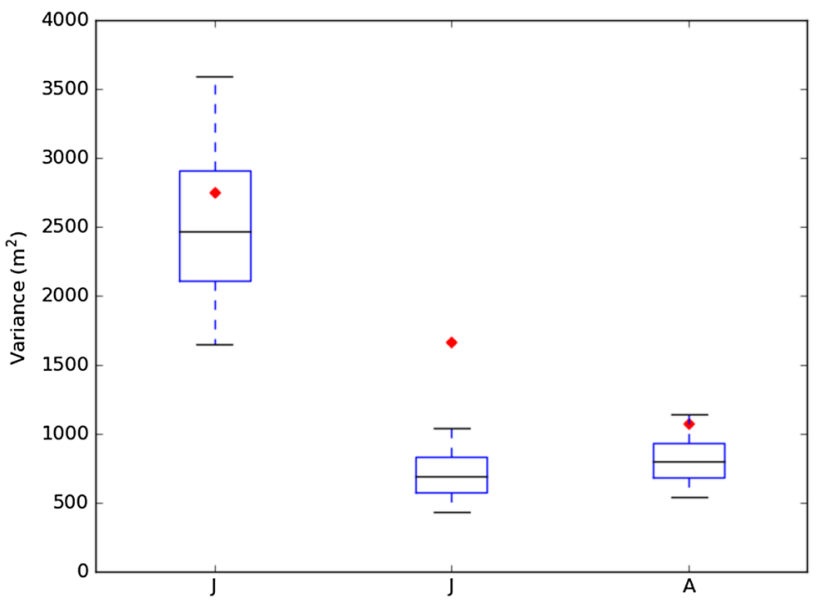

Fig. 6 Distribution of variances of the D\&W Index, calculated using the multiple samples. The box plots represent the upper and lower quartiles, and the whiskers extend to the 5th and 95th percentiles. The black horizontal line represents the median value and the red diamond the observed variance from ERA-Interim

pathway is correctly represented in the model, it will still underestimate the strength of the teleconnection.

To identify a possible cause of the low variance in the model D\&W Index in July and August we examine the relationship between geopotential height in this region and precipitation in the North Indian Summer Monsoon region (NISM), a region first defined in Ding and Wang (2007). We know from observations that there is a significant correlation between precipitation in this region and the $\mathrm{D} \& \mathrm{~W}$ Index (correlations of $0.51,0.61,0.56$ for June, July and August respectively) as a result of a Gill-type response to the off-equatorial diabatic heating associated with the ISM (Gill 1980; Ding and Wang 2005). Therefore if the model does not represent the relationship between these regions well, this will affect its ability to correctly simulate the CGT.

Figure 7a shows the observed and model correlations between the D\&W Index and NISM precipitation. During July and August, when the variance in the D\&W Index is reduced, the model underestimates the correlation between NISM precipitation and the D\&W Index (Fig. 7a) and also underestimates the variance in NISM precipitation during these months (Fig. 7b). This suggests that the poor variance of the D\&W Index in July and August may be linked to poor representation of NISM precipitation in the model.

It was shown in Ding et al. (2011) that the CGT pattern is favoured in summers preceding the peak phases of ENSO. Correlating the difference in the Nino3.4 Index in the preceding winter (DJF) and the subsequent winter against individual centres of action results in negative but not significant correlations. The equivalent model correlations are also not significant but are generally less negative than the observations (not shown). Therefore while the CGT itself may be correlated 

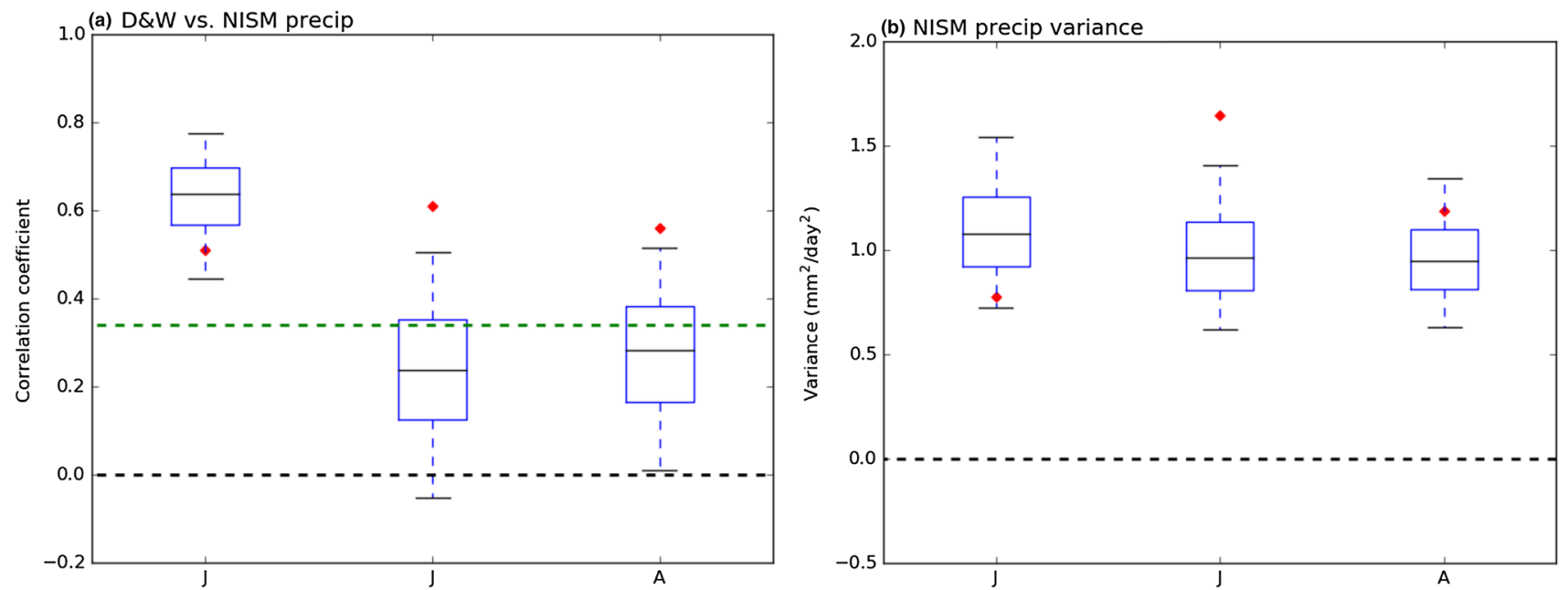

Fig. 7 Same as Fig. 6, but for a the correlation coefficient between the D\&W Index and NISM precipitation and $\mathbf{b}$ the variance of NISM precipitation. The green dashed line on a represents the 5\% significance level

with ENSO, there is no obvious link between ENSO and the individual centres of action. This may be because there are a number of other drivers for each of the centres of action individually which may mask the influence of ENSO.

\subsection{Rossby wave source}

The CGT mechanism relies on the generation and propagation of Rossby waves. The Rossby wave source (RWS) describes the forcing of Rossby waves by the divergent flow, and can be written as:

$R W S=-\zeta D-\mathbf{v}_{\chi} \cdot \nabla \zeta$

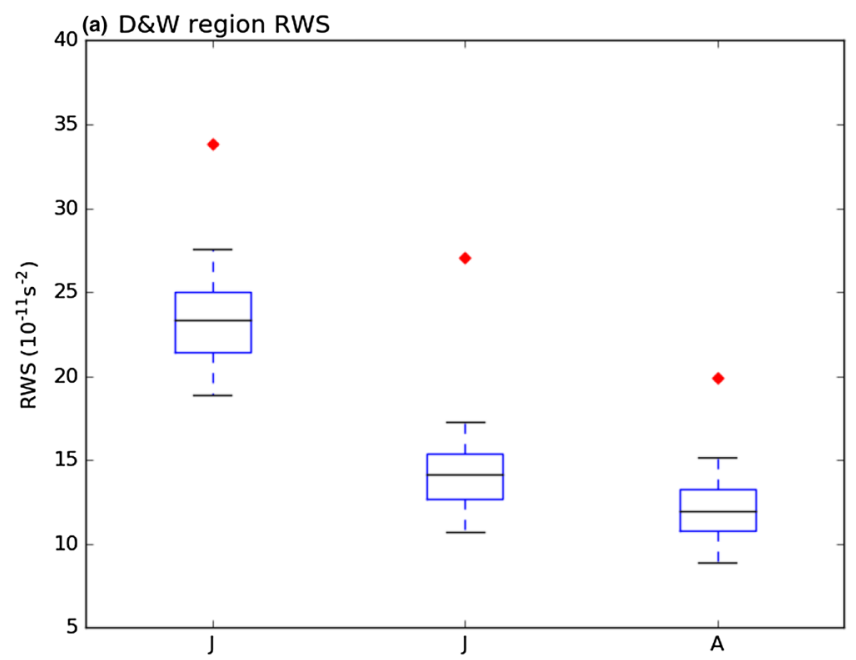

Fig. 8 a Rossby wave source (RWS) in the model (box plots) and observations (red diamond) and $\mathbf{b}$ variance in the RWS in the model and observations. In both panels the box plots represent the upper and where $\zeta$ is the absolute vorticity, $D$ is the horizontal divergence and $\mathbf{v}_{\chi}$ is the divergent part of the wind field. This is derived from the vorticity equation for a single level in the atmosphere (e.g. James 1995), and the RWS is calculated using the $u$ and $v$ components of the wind at $200 \mathrm{hPa}$. Given the likely interaction between Rossby waves generated by the ISM and the CGT, we compare the RWS in the model to ERA-Interim to help understand the role of any errors in RWS in the representation of the CGT in the model. We first focus on the D\&W region, given its key role as a centre of action of the CGT, and the fact that there is a significant correlation between the D\&W Index and RWS located near the D\&W region in July and August $(-0.50$ and -0.42 respectively).

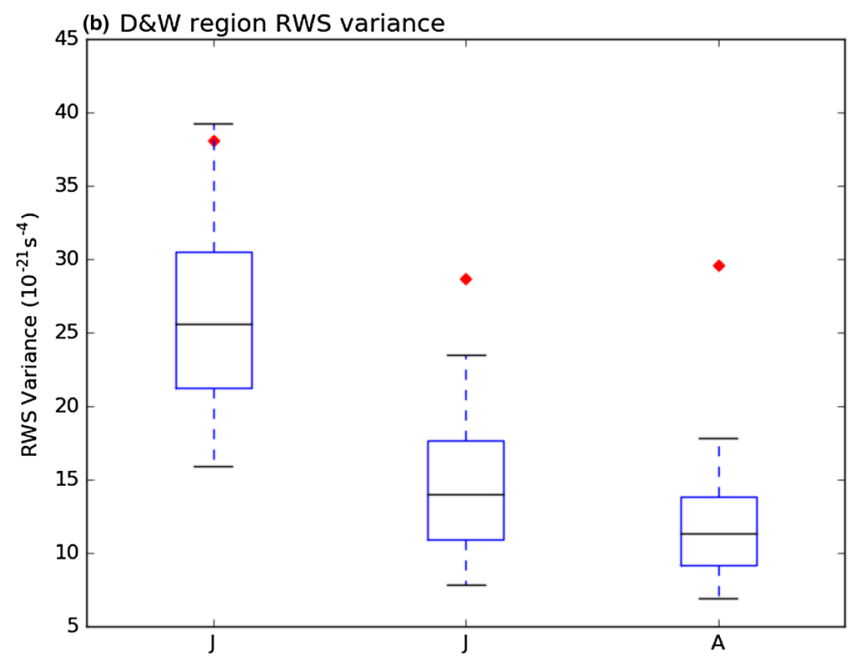

lower quartiles, and the whiskers extend to the 5th and 95th percentiles. The black horizontal line represents the median value and the red diamond the observed value from ERA-Interim 
Figure 8a shows the RWS averaged over the D\&W region in the model and observations. It is clear that the model RWS in this region is too low in all months, with the observations lying well outside the model distribution. The variance of the RWS in this region is also too low (Fig. 8b) in the model in both July and August, and to a slightly lesser extent in June. If the strength and variance of the forcing in this region are not accurately represented then Rossby waves that are excited may be weaker than observed and this will affect their propagation characteristics and as such will result in errors in the modelled CGT.

To gain an understanding of the reasons for the differences seen in Fig. 8 we examine the mean RWS across a wider region. All of the panels in Fig. 9 are for August only, as this month has the strongest CGT wavetrain and the patterns are representative of those seen in June and July (not shown). Figure 9a, b show the mean August RWS term, calculated using Eq. (1), in ERA-Interim and the model ensemble mean respectively in the coloured contours, and the 200 $\mathrm{hPa}$ zonal wind in the black contours. The first thing we note is that the centre of positive RWS located at approximately $40^{\circ} \mathrm{N}, 60^{\circ} \mathrm{E}$, which, along with the source over the Mediterranean, is a major wave source (Enomoto et al. 2003), is broader and is located further to the north in the model than in ERA-Interim. This appears to be associated with a northward displacement of the model jet stream by several degrees when compared to ERA-Interim, and also explains the lower than observed RWS in the D\&W region in the model shown in Fig. 8a. This displacement in both RWS and jet location is also present in both June and July (not shown).

Figure $8 \mathrm{~b}$ shows that the variance of the RWS in the $\mathrm{D} \& \mathrm{~W}$ region is lower in the model than in observations, however we see from Fig. 9c, d that this is generally not the case over a wider region. Indeed, in most parts of the region of interest the variance of the RWS in ERA-Interim (Fig. 9c) is lower than in the model (Fig. 9d). This is because the amplitude of the RWS in the model is generally larger, therefore horizontal gradients in the RWS are larger. This means that horizontal displacements in the centres of maxima and minima from year-to-year give greater variance. The northward position of the jet stream in the model may also account for the generally larger variance in RWS between $50^{\circ} \mathrm{N}$ and $60^{\circ} \mathrm{N}$, due to the increased vorticity gradient here.

The mean divergence field ( $D$ in Eq. 1 ) is shown in Figs. 9e (ERA-Interim) and 9f (model). The centre of negative divergence (convergence) located at approximately $40^{\circ} \mathrm{N}, 60^{\circ} \mathrm{E}$ (in the same location as the centre of large RWS in Fig. 9a) is both larger in magnitude and located further to the north in the model than in ERA-Interim. This centre of convergence was shown to be localised in this region by the presence of the Zagros mountain chain (Rodwell and Hoskins 1996). Where the jet is located may determine where the divergence and convergence is, but we know, by comparing to the RWS computed from the rotational flow of ERA-Interim with the model divergent flow, that errors in the RWS primarily come from errors in the divergent flow (not shown). The errors in divergence are largest over both the Arabian Sea and the Bay of Bengal. Here, the divergence is much greater in the model than in ERA-Interim, associated with too much precipitation in the model in these regions (Figs. 9g, h). If the greater precipitation in the model is also associated with larger monsoon variability, this may affect the forcing of the CGT in the model. The RWS term is also dominated by the divergence component, and therefore the convergence in the model (which is both too strong and located in the wrong place) is likely to be an important factor in the errors in RWS in the model. These errors in the RWS may impact on European summer forecast skill through errors in the CGT, so more accurate representation of the link between monsoon heating and the extratropical circulation is likely to be important for improving European summer forecasts.

We also note that the jet biases over the Mediterranean are much smaller than over west-central Asia, and the location of the centre of convergence in the model in this region closer resembles ERA-Interim. Where there are larger wind biases over west-central Asia there is a greater displacement of the centre of convergence, and this strengthens the argument that the jet location is an important factor in these errors.

The propagation of Rossby waves generated in this region relies on the jet stream, which acts as a waveguide. As seen in Figs. 9a, b, the model jet stream is located too far to the north over Asia. It can be seen from Fig. 10 that there is a clear northward bias in the position of the jet over much of the northern hemisphere, particularly in June, July and August. This is shown by the positive biases to the north and negative biases to the south of the observed jet stream. The wind biases are smallest early on in the simulation, when the maximum biases are around $4 \mathrm{~ms}^{-1}$. However, these biases quickly become larger, reaching a maximum of around $8 \mathrm{~ms}^{-1}$ in June. The magnitude of the maximum biases then remains approximately constant for the remainder of the hindcast period. The largest wind biases are seen in the RWS region over Asia which means that Rossby waves forced in this region will have different wave propagation characteristics to reality-they may propagate at the incorrect speed, in the wrong direction or may not propagate at all. The combination of the errors in RWS along with the model jet biases are likely to be crucial in the poor representation of the CGT in the model. 
(a) ERA-I RWS $\left(10^{-11} \mathrm{~s}^{-2}\right), 200 \mathrm{hPa}$ zonal wind

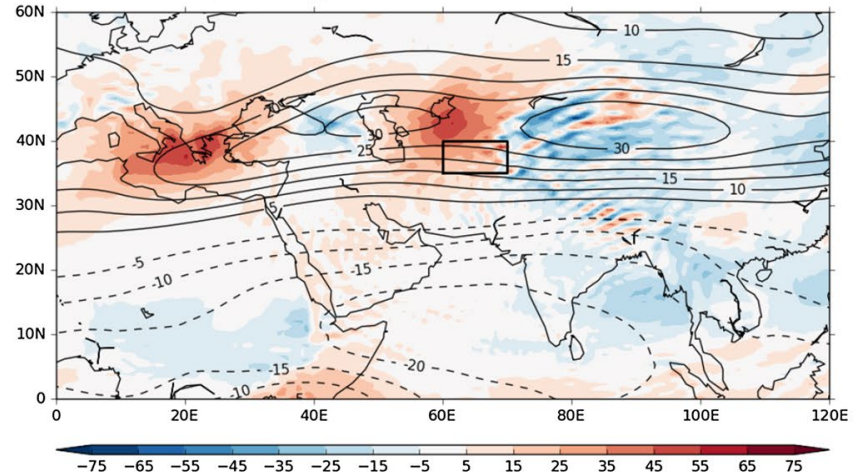

(c) ERA-I RWS variance $\left(10^{-20} \mathrm{~s}^{-4}\right)$

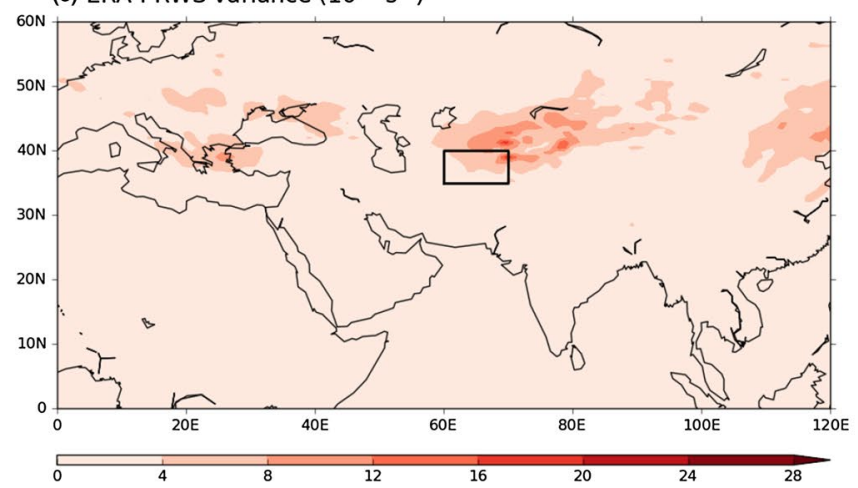

(e) ERA-I divergence $\left(10^{-7} \mathrm{~s}^{-1}\right)$

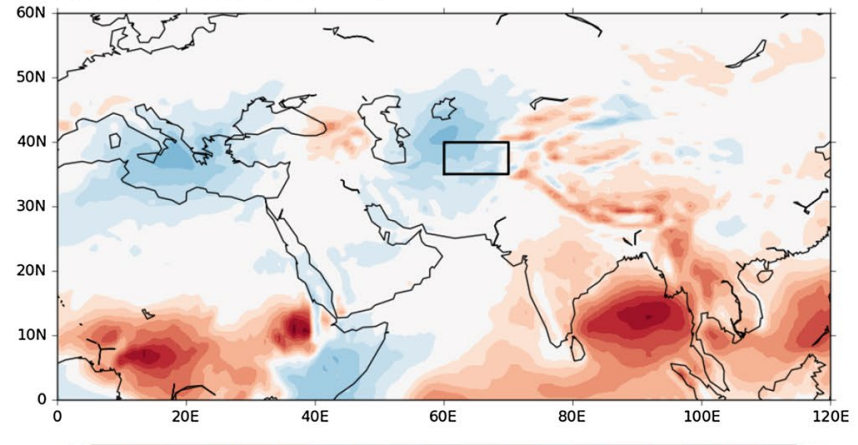

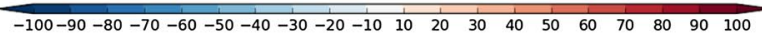

(g) GPCP precipitation ( $\mathrm{mm} /$ day)

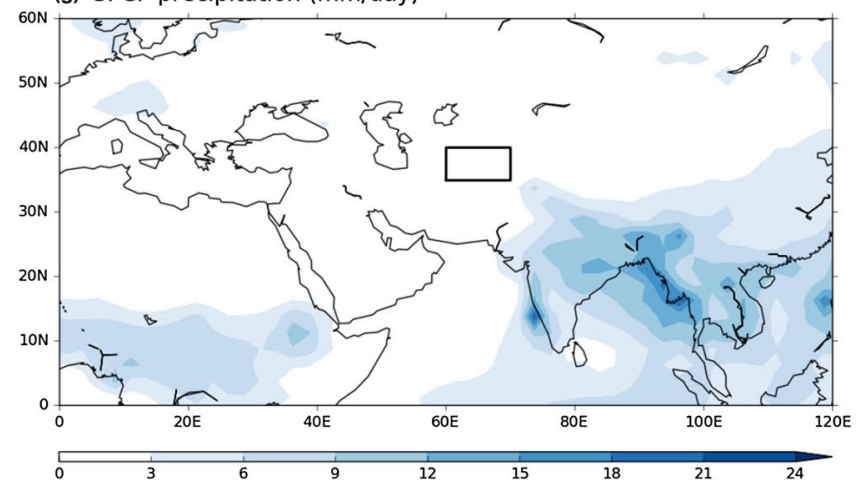

Fig. 9 a ERA-Interim and b model ensemble mean RWS term (filled contours) and $200 \mathrm{hPa}$ zonal wind (black contours). c ERA-Interim and $\mathbf{d}$ model variance of the RWS term. The model variance is for all members concatenated together. e ERA-Interim and $\mathbf{f}$ model ensem- (b) Model RWS $\left(10^{-11} \mathrm{~s}^{-2}\right), 200 \mathrm{hPa}$ zonal wind

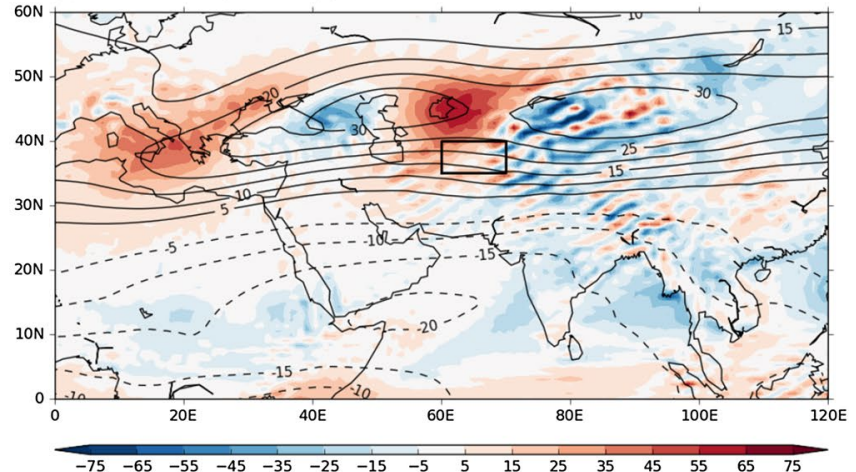

(d) Model RWS variance $\left(10^{-20} \mathrm{~s}^{-4}\right)$

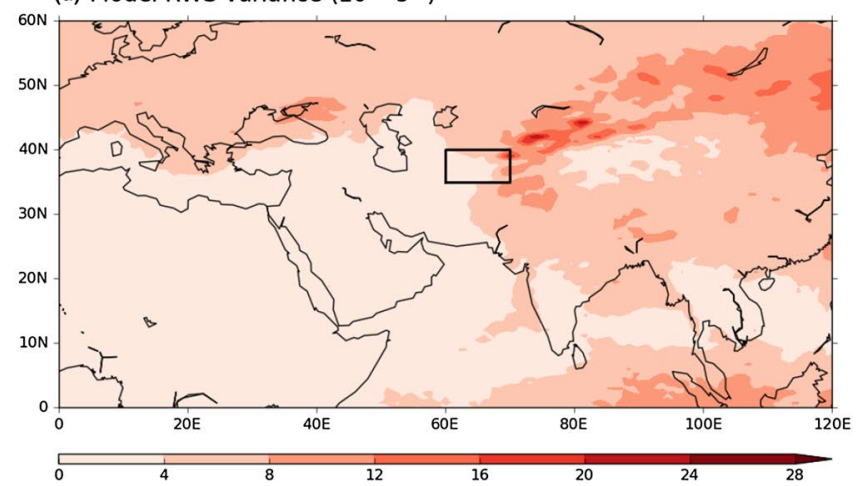

(f) Model divergence $\left(10^{-7} \mathrm{~s}^{-1}\right)$

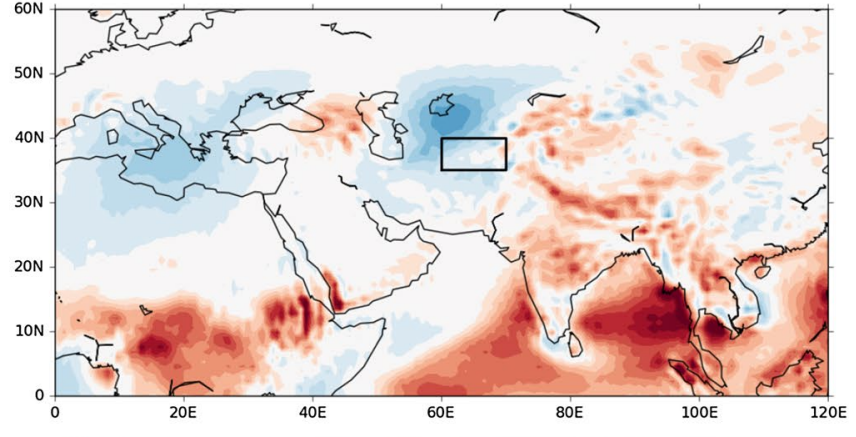

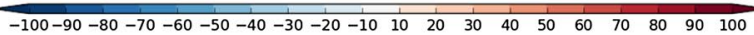

(h) Model precipitation ( $\mathrm{mm} /$ day)

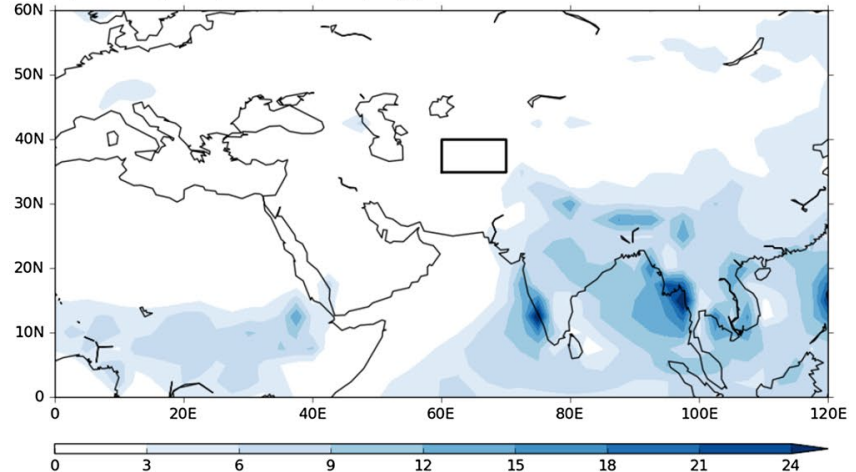

ble mean divergence. $\mathbf{g}$ GPCP and $\mathbf{h}$ model ensemble mean precipitation. All panels are for August, and the D\&W region is marked as a box 

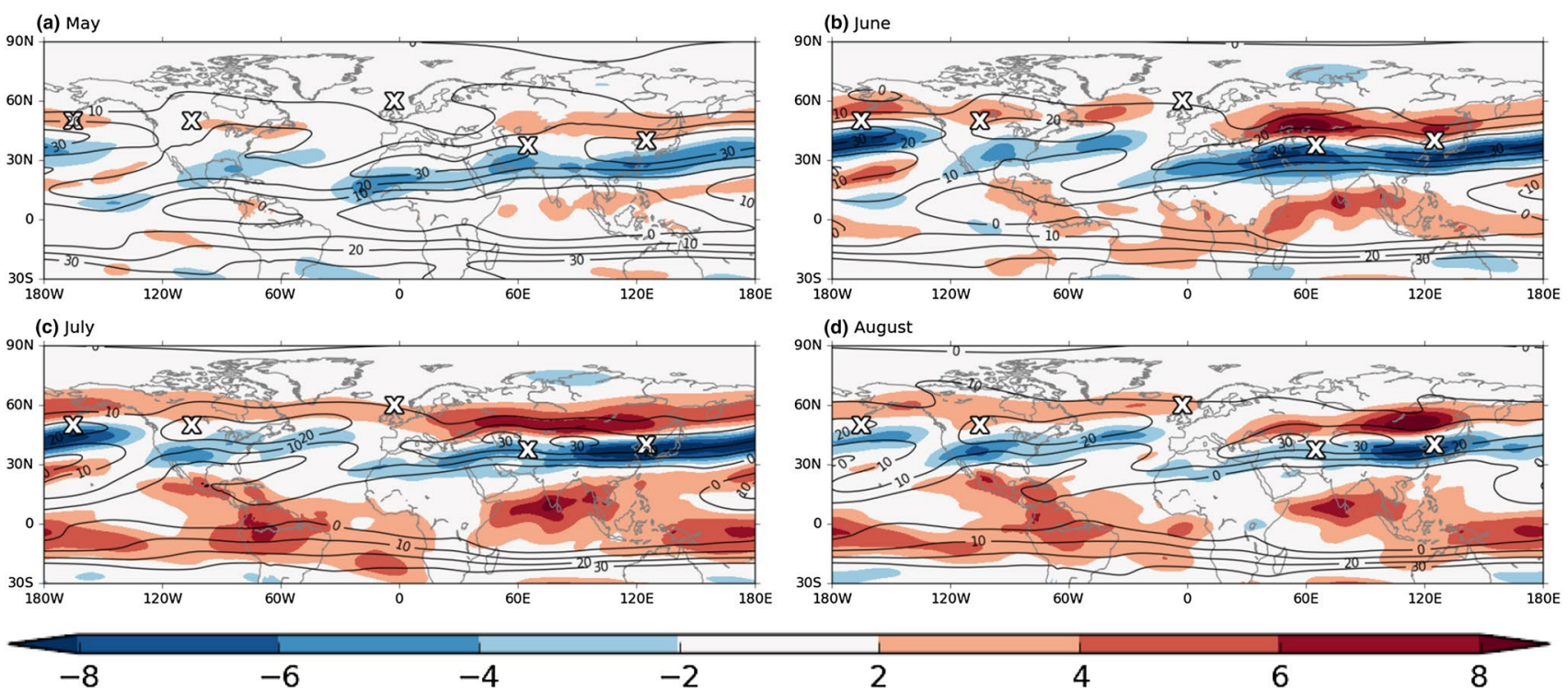

Fig. 10 Model $200 \mathrm{hPa}$ zonal wind bias (filled contours, $\mathrm{ms}^{-1}$ ), defined as the model ensemble mean minus ERA-Interim zonal wind, and ERA-I $200 \mathrm{hPa}$ zonal wind (black contours) for a May, b June, c July and $\mathbf{d}$ August. To show the position of the observed jet, only the

\section{Conclusions}

The circumglobal teleconnection (CGT) has a major role in influencing observed weather patterns in the northern hemisphere summer. The variations of the wavetrain associated with the CGT cause significant seasonal temperature and precipitation anomalies in many areas, including Europe. Accurate prediction of the CGT is therefore important in improving seasonal forecasts for the European summer.

In this paper we analysed the ability of a version of the ECMWF seasonal forecast model to represent the CGT. The model representation of the CGT was found to be too weak, particularly in July and August, when the observed correlations associated with the CGT wavetrain are at their strongest and the impact of the CGT on European weather and climate is large. It was also found that the model underestimates the strength of the correlation between many of the centres of action of the CGT. The model performance in August was found to be particularly poor, with the observed correlation between the D\&W Index and the NPAC, NAM and NWEUR regions lying in the upper end of the distribution of model correlations (Fig. 4). The model is able to capture the relationship between the D\&W and EASIA regions in all months, but further downstream from this region correlations are much weaker than observed (Fig. 5). In general, the model tends to underestimate the strength of the correlations in August. We have looked at the relationship between the Rossby wave source and the monsoon heating but we have not looked at the relationship between the CGT

$0,10,20$ and $30 \mathrm{~ms}^{-1}$ isotachs have been plotted. For orientation, the location of the centres of action of the CGT are marked with white crosses

pattern and other drivers of tropical precipitation, and this may merit further investigation as a cause of the lack of skill for the CGT.

We identified several errors in aspects of the model's simulation which may be important for the generation and maintenance of the CGT, including:

1. Weak variability in the $D \& W$ region $\mathrm{We}$ found that the model accurately captures the strength of interannual variability in this region in this region in June, but performs much worse in July and August. This means that, assuming the other drivers of variability in remote regions remain the same, the $\mathrm{D} \& \mathrm{~W}$ Index will explain less of the variance.

2. Poor representation of the link between the $D \& W$ Index and NISM precipitation Weak variability in the D\&W Index may be related to a weak correlation with NISM precipitation and weak variability in NISM precipitation during July and August. The similarity between the location of the observations in the box plots in Figs. 6 and 7 suggests that poor representation by the model of the relationship between these regions in July and August is an important factor in explaining the low model variance in the D\&W Index in these months.

3. Errors in the RWS There are errors in the RWS in and around the D\&W region. In particular, the main centre of RWS is stronger and is displaced northwards and eastwards in June, July and August. This error is largely related to errors in the divergence, and is associated with 
greater than observed precipitation over the Bay of Bengal and Arabian Sea.

4. Errors in the jet location There is a northward displacement of the jet around the D\&W region in June, July and August, which may be partially responsible for the displacement of the centres of convergence and RWS. There is also a displacement of the jet in much of the northern hemisphere, and this error, along with errors in the forcing of Rossby waves, is likely to be a key factor in the poor representation of the CGT in the model, and is a major contributor to the poor forecast skill over Europe.

It seems likely that the pattern of reduced skill in Fig. 1, with negative correlations located at the centres of action of the CGT, including over Europe, is related to the poor representation of the CGT in the model, either as a result of a poor representation of the monsoon heating and its associated Rossby wave response, or biases in the jet location. Improving the simulation of the CGT is therefore likely to be important for improving seasonal forecasts for Europe. This also raises the question that if the model's representation of the CGT was improved, would that lead to an improvement in forecast skill for the European summer? To address this question, sensitivity experiments are currently underway imposing the observed circulation in several centres of action along the CGT pathway to explore the impact on forecast skill for European summer weather. Analysis of these experiments will be the focus of a subsequent paper.

Acknowledgements JDB and SJW are funded by the Natural Environment Research Council (NERC) through the SummerTIME Project (NE/M005909/1). SJW is also supported by the National Centre for Atmospheric Science, a NERC collaborative centre under contract R8/ H12/83/001. LHB is funded by NERC through the IMPETUS project (NE/L010488/1). We are grateful to the European Centre for MediumRange Weather Forecasts for the use of their computing resources.

Open Access This article is distributed under the terms of the Creative Commons Attribution 4.0 International License (http://creativeco mmons.org/licenses/by/4.0/), which permits unrestricted use, distribution, and reproduction in any medium, provided you give appropriate credit to the original author(s) and the source, provide a link to the Creative Commons license, and indicate if changes were made.

\section{References}

Adler RF, Huffman GJ, Chang A, Ferraro R, Xie PP, Janowiak J, Rudolf B, Schneider U, Curtis S, Bolvin D, Gruber A, Susskind J, Arkin $P$, Nelkin E (2003) The version-2 global precipitation climatology project (GPCP) monthly precipitation analysis (1979-present). J Hydrometeor 4(6):1147-1167. https://doi.org/10.1175/15257541(2003)004\%3c1147:TVGPCP\%3e2.0.CO;2
Ashok K, Guan Z, Yamagata T (2001) Impact of the Indian Ocean Dipole on the Relationship between the Indian Monsoon Rainfall and ENSO. Geophys Res Lett 28(23):4499-4502

Blackburn M, Methven J, Roberts N et al (2008) Large-scale context for the UK floods in summer 2007. Weather 63(9):280

Dee DP, Uppala SM, Simmons aJ, Berrisford P, Poli P, Kobayashi S, Andrae U, Balmaseda Ma, Balsamo G, Bauer P, Bechtold P, Beljaars aCM, van de Berg L, Bidlot J, Bormann N, Delsol C, Dragani R, Fuentes M, Geer aJ, Haimberger L, Healy SB, Hersbach H, Hólm EV, Isaksen L, Kållberg P, Köhler M, Matricardi M, Mcnally aP, Monge-Sanz BM, Morcrette JJ, Park BK, Peubey C, de Rosnay P, Tavolato C, Thépaut JN, Vitart F (2011) The ERAinterim reanalysis: configuration and performance of the data assimilation system. Quart J Roy Meteorol Soc 137(656):553597. https://doi.org/10.1002/qj.828

Ding Q, Wang B (2005) Circumglobal teleconnection in the northern hemisphere summer. J Clim 18(17):3483-3505. https://doi. org/10.1175/JCLI3473.1

Ding Q, Wang B (2007) Intraseasonal teleconnection between the summer Eurasian wave train and the Indian monsoon. J Clim 20(15):3751-3767

Ding Q, Wang B, Wallace JM, Branstator G (2011) Tropicalextratropical teleconnections in boreal summer: observed interannual variability. J Clim 24(7):1878-1896. https://doi. org/10.1175/2011JCLI3621.1

Dunstone N, Smith D, Scaife A, Hermanson L, Eade R, Robinson N, Andrews M, Knight J (2016) Skilful predictions of the winter North Atlantic Oscillation one year ahead. Nat Geosci 9(11):809-814

Enomoto T, Hoskins BJ, Matsuda Y (2003) The formation mechanism of the Bonin high in August. Quart J Roy Meteorol Soc 129(587):157-178

Folland CK, Knight J, Linderholm HW, Fereday D, Ineson S, Hurrell JW (2009) The Summer North Atlantic oscillation: past, present, and future. J Clim 22(5):1082-1103

Gill A (1980) Some simple solutions for heat-induced tropical circulation. Quart J Roy Meteorol Soc 106(449):447-462

Godbole RV (1977) The composite structure of the monsoon depression. Tellus 29(1):25-40

Ha KJ, Chu JE, Lee JY, Wang B, Hameed SN, Watanabe M (2012) What caused the cool summer over northern Central Asia, East Asia and central North America during 2009? Environ Res Lett 7(4):044,015

James IN (1995) Introduction to circulating atmospheres. Cambridge University Press, Cambridge

Johnson SJ, Turner A, Woolnough S, Martin G, MacLachlan C (2016) An assessment of Indian monsoon seasonal forecasts and mechanisms underlying monsoon interannual variability in the met office GloSea5-GC2 system. Clim Dyn 1-19

Kim HM, Webster PJ, Curry JA, Toma VE (2012) Asian summer monsoon prediction in ECMWF System 4 and NCEP CFSv2 retrospective seasonal forecasts. Clim Dyn 39(12):2975-2991

Lee JY, Wang B, Ding Q, Ha KJ, Ahn JB, Kumar A, Stern B, Alves $\mathrm{O}$ (2011) How predictable is the northern hemisphere summer upper-tropospheric circulation? Clim Dyn 37(5-6):1189-1203

Liu F, Wang B (2013) Mechanisms of global teleconnections associated with the Asian summer monsoon: an intermediate model analysis. J Clim 26(5):1791-1806

Molteni F, Stockdale T, Balmaseda M, Balsamo G, Buizza R, Ferranti L, Magnusson L, Mogensen K, Palmer T, Vitart F (2011) The new ECMWF seasonal forecast system (System 4). European Centre for Medium-Range Weather Forecasts

Moon JY, Wang B, Ha KJ, Lee JY (2013) Teleconnections associated with northern hemisphere summer monsoon intraseasonal oscillation. Clim Dyn 40:2761-2774. https://doi.org/10.1007/ s00382-012-1394-0 
Raicich F, Pinardi N, Navarra A (2003) Teleconnections between Indian monsoon and Sahel rainfall and the mediterranean. Int J Climatol 23(2):173-186

Rajeevan M, Unnikrishnan C, Preethi B (2012) Evaluation of the ENSEMBLES multi-model seasonal forecasts of Indian summer monsoon variability. Clim Dyn 38(11-12):2257-2274

Rex DF (1950) Blocking action in the middle troposphere and its effect upon regional climate. Tellus 2(4):275-301

Rodwell MJ, Hoskins BJ (1996) Monsoons and the dynamics of deserts. Quart J Roy Meteorol Soc 122(534):1385-1404. https ://doi.org/10.1002/qj.49712253408

Ropelewski CF, Halpert MS (1987) Global and regional scale precipitation patterns associated with the El Niño/Southern oscillation. Mon Weather Rev 115(8):1606-1626

Saeed S, Van Lipzig N, Müller WA, Saeed F, Zanchettin D (2014) Influence of the circumglobal wave-train on European summer precipitation. Clim Dyn 43(1-2):503-515

Sardeshmukh PD, Hoskins BJ (1988) The generation of global rotational flow by steady idealized tropical divergence. J Atmos Sci 45(7):1228-1251

Scaife AA, Copsey D, Gordon C, Harris C, Hinton T, Keeley S, O’Neill A, Roberts M, Williams K (2011) Improved Atlantic winter blocking in a climate model. Geophys Res Lett 38(23)

Shukla J, Paolino DA (1983) The Southern oscillation and long-range forecasting of the summer monsoon rainfall over India. Mon Weather Rev 111(9):1830-1837
Sperber K, Annamalai H, Kang IS, Kitoh A, Moise A, Turner A, Wang B, Zhou T (2013) The Asian summer monsoon: an intercomparison of CMIP5 vs. CMIP3 simulations of the late 20th century. Clim Dyn 41(9-10):2711-2744

Stockdale TN, Molteni F, Ferranti L (2015) Atmospheric initial conditions and the predictability of the Arctic Oscillation. Geophys Res Lett 42(4):1173-1179

Tyrlis E, Škerlak B, Sprenger M, Wernli H, Zittis G, Lelieveld J (2014) On the linkage between the Asian summer monsoon and Tropopause fold activity over the Eastern Mediterranean and the Middle East. J Geophys Res Atmos 119(6):3202-3221

Weisheimer A, Schaller N, O'Reilly C, MacLeod DA, Palmer T (2017) Atmospheric seasonal forecasts of the twentieth century: multidecadal variability in predictive skill of the winter North Atlantic Oscillation (NAO) and their potential value for extreme event attribution. Quart J Roy Meteorol Soc 703:917-926

Wilks DS (2011) Statistical methods in the atmospheric sciences, vol 100. Academic press, USA

Wu B, Zhou T, Li T (2016) Impacts of the Pacific-Japan and circumglobal teleconnection patterns on the interdecadal variability of the East Asian summer monsoon. J Clim 29(9):3253-3271 